\title{
Severe cases of ectopically erupting maxillary canine with excessive mesial angulation
}

\author{
Yo Taguchi*1, Sachiko Hayashi-Sakai*2 and Takashi Tsuda*2 \\ ${ }^{* 1}$ Division of Pediatric Dentistry, Department of Oral Health Science, Course for Oral Science, \\ Niigata University Graduate School of Medical and Dental Sciences, \\ *2 Pediatric Dental Clinic of Niigata University Medical and Dental Hospital \\ 2-5274 Gakkocho-dori, Chuo-ku, Niigata 951-8514, JAPAN
}

\begin{abstract}
The aim of the present study was to examine retrospectively how best to treat severe cases of ectopically erupting maxillary canines with mesial angulation exceeding 50 degrees. From the ectopically erupting canines diagnosed at the Pediatric Dental Clinic of Niigata University Hospital, we selected for our study 14 severe cases in which mesial angulation exceeded 50 degrees. Nine ectopically erupting canines could be aligned within the arch after traction, and two canines are in the course of treatment, while three canines were removed. In the removed canines, the vertical length from the occlusal line of the crown top was shorter than that in the aligned canines with similar initial condition. This means that the vertical length to the occlusal line of the impacted canine influences the treatment complexity. In four similar ectopically erupting canines in which mesial inclination was nearly 80 degrees or greater and vertical length was over 30 millimeters with Sector 1 or 2 positioning distal to the midline of the root of its adjacent lateral incisor, the initial disruptive conditions were improved after extraction of the predecessor and/or fenestration of the affected canine. It is concluded that traction should be postponed until a few months after extraction of the predecessor if the ectopically erupting canine is located far away from the occlusal line (over 30 millimeters) and its mesial inclination is more than nearly 80 degrees; also that this treatment plan should be limited to cases in which the crown top belongs to Sector 1 and 2.
\end{abstract}

\section{Introduction}

The maxillary canine is the second most commonly impacted/non-erupted tooth after the maxillary central incisor in Japanese children and adolescents ${ }^{1)}$. Ectopic eruption of the maxillary canine is found in $1.5 \%$ to $2 \%$ of children during the mixed dentition period $^{2-4)}$. Not only does impaction of the canine result in functional and aesthetic problems, but it also leads to a high frequency of root resorption in the adjacent teeth ${ }^{5-7)}$. The early detection and intervention of an affected canine are therefore essential to reduce treatment duration and to gain

Received on September 28, 2007

Accepted on January 29, 2008
Key words

Ectopic eruption, Eruption disturbance, Impaction, Maxillary canine, Uneruption a good outcome as well as to lessen the young patient's discomfort.

A number of researchers ${ }^{8-13)}$ have focused on the prediction of impacted canine, as early extraction of its predecessor may prevent progress of the eruption disorder. As for the relationship between the initial condition of ectopically erupting canines and the performed treatments, Kurol et al. ${ }^{14)}$ calculated the rate of success for realignment of affected canines at 1 year after extraction of primary canines in relation to their initial position, mesial or distal to the midline of the lateral incisor. Taguchi et al. ${ }^{13)}$ demonstrated that excessive axial angulation to the midline of the ectopically erupting canine on the orthopantomogram was the most prominent feature in cases of removal. The mean angulation was 

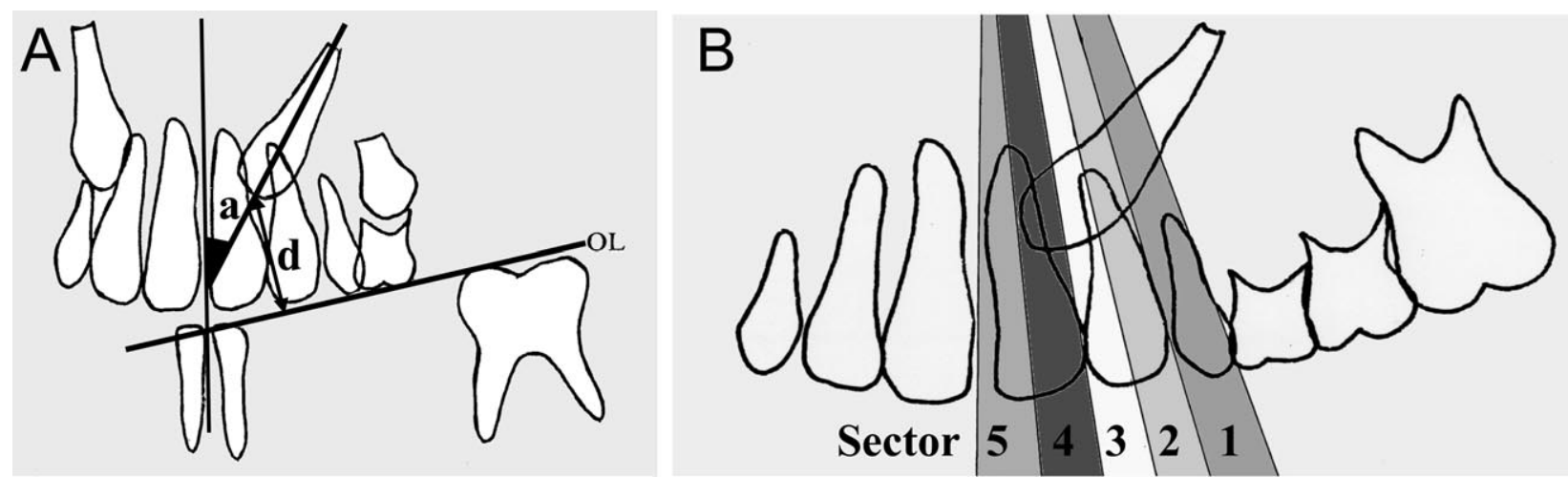

Fig. 1 Measurement of the crown top of ectopically erupting canines in the orthopantomogram

The vertical length (A) to occlusal line (OL) can be measured in (d) millimeters and the axial angulation to midline in (a) degrees. Sector (B) is defined as the position of the crown top overlapping the adjacent lateral or central incisor root.

beyond 50 degrees in cases of removal but the mean value was about 30 degrees in cases of traction and successful alignment. Although early detection for ectopically developing canine is desirable, it is not always feasible because a patient may visit the dentist too late to make an early diagnosis. It may be also difficult to make early intervention such as extraction of their predecessors because the axial direction and/or position of a canine germ may be already abnormal even in the early growing stage.

In addition to the axial angulation, it was also reported that the vertical length to the occlusal line of the affected canine was related to the performed treatment ${ }^{13,14)}$. In removal cases of the ectopically erupting canine, the mean vertical length of them showed significantly longer than that in the cases successfully guided and aligned within the dental $\operatorname{arch}^{13)}$.

The aim of the present study was to investigate retrospectively how best to treat severe cases of ectopically erupting canine with mesial angulation exceeding 50 degrees, and to examine the influence of the vertical length of the affected canine on the treatment in the severe cases.

\section{Materials and Methods}

The present retrospective observational study analyzed patient records collected from the Pediatric Dental Clinic of Niigata University Medical and Dental Hospital. The diagnosis of an aberrant eruptive path of the maxillary canine was based on orthopantomograms of patients taken during routine assessments of oral health, according to the following criteria
Table 1 Distribution of patients with ectopic canines

\begin{tabular}{cccc}
\hline Case No. & Gender & $\begin{array}{c}\text { Objective } \\
\text { side }\end{array}$ & $\begin{array}{c}\text { Age at } \\
\text { detection }\end{array}$ \\
\hline 1 & $\mathrm{~F}$ & $\mathrm{R}$ & $9 \mathrm{y} 8 \mathrm{~m}$ \\
2 & $\mathrm{M}$ & $\mathrm{R}$ & $12 \mathrm{y} 2 \mathrm{~m}$ \\
3 & $\mathrm{M}$ & $\mathrm{R}$ & $14 \mathrm{y} 10 \mathrm{~m}$ \\
4 & $\mathrm{M}$ & $\mathrm{L}$ & $11 \mathrm{y} 9 \mathrm{~m}$ \\
5 & $\mathrm{~F}$ & $\mathrm{~L}$ & $12 \mathrm{y} 10 \mathrm{~m}$ \\
6 & $\mathrm{~F}$ & $\mathrm{~L}$ & $13 \mathrm{y} 2 \mathrm{~m}$ \\
7 & $\mathrm{~F}$ & $\mathrm{R}$ & $11 \mathrm{y} 5 \mathrm{~m}$ \\
8 & $\mathrm{~F}$ & $\mathrm{~L}$ & $11 \mathrm{y} 0 \mathrm{~m}$ \\
9 & $\mathrm{~F}$ & $\mathrm{~L}$ & $8 \mathrm{y} 4 \mathrm{~m}$ \\
10 & $\mathrm{~F}$ & $\mathrm{~L}$ & $8 \mathrm{y} 6 \mathrm{~m}$ \\
11 & $\mathrm{M}$ & $\mathrm{L}$ & $9 \mathrm{y} 1 \mathrm{~m}$ \\
\hline 12 & $\mathrm{~F}$ & $\mathrm{R}$ & $11 \mathrm{y} 0 \mathrm{~m}$ \\
13 & $\mathrm{~F}$ & $\mathrm{R}$ & $11 \mathrm{y} 2 \mathrm{~m}$ \\
14 & $\mathrm{M}$ & $\mathrm{L}$ & $12 \mathrm{y} 7 \mathrm{~m}$ \\
\hline
\end{tabular}

provided in our previous report ${ }^{15)}$.

1. The axial angulation to the midline (a) and the vertical length to the occlusal line (d) of the affected canine were measured to determine the initial status (Fig. 1A). When the difference between the two sides was beyond 5 degrees in axial angulation to the midline or more than $5 \mathrm{~mm}$ in length to the occlusal line, the canine was diagnosed as having an aberrant path of eruption.

2. The extent to which the cusp tip of the canine overlapped the adjacent lateral or central incisor root was estimated (Fig. 1B). This sector classification method was most useful for determining whether the eruptive path was abnormal bilaterally. 
Table 2 Initial condition of each case

\begin{tabular}{cccccc}
\hline Case No. & $\begin{array}{c}\text { Mesial } \\
\text { inclination }\end{array}$ & $\begin{array}{c}\text { Vertical length } \\
(\mathrm{mm})\end{array}$ & Sector & $\begin{array}{c}\text { Position } \\
\text { (Palatal side) }\end{array}$ & $\begin{array}{c}\text { Endodontic treatment } \\
\text { of the predecessor }\end{array}$ \\
\hline 1 & 50 & 21 & 3 & $\mathrm{Y}$ & $\mathrm{Y}$ \\
2 & 50 & 20 & 1 & $\mathrm{Y}$ & $\mathrm{Y}$ \\
3 & 51 & 16 & 4 & $\mathrm{Y}$ & \\
4 & 60 & 19 & 3 & $\mathrm{Y}$ & $\mathrm{Y}$ \\
5 & 79 & 37 & 1 & & $\mathrm{Y}$ \\
6 & 81 & 20 & 4 & & \\
7 & 82 & 27 & 3 & & \\
8 & 86 & 23 & 1 & & $\mathrm{Y}$ \\
9 & 87 & 33 & 2 & & $\mathrm{Y}$ \\
10 & 90 & 33 & 1 & $\mathrm{Y}$ & $\mathrm{Y}$ \\
11 & 90 & 30 & 1 & $\mathrm{Y}$ & \\
\hline 12 & 62 & 23 & 4 & 3 & \\
13 & 72 & 25 & 5 & & \\
\hline 14 & 76 & 26 & & & \\
\hline
\end{tabular}
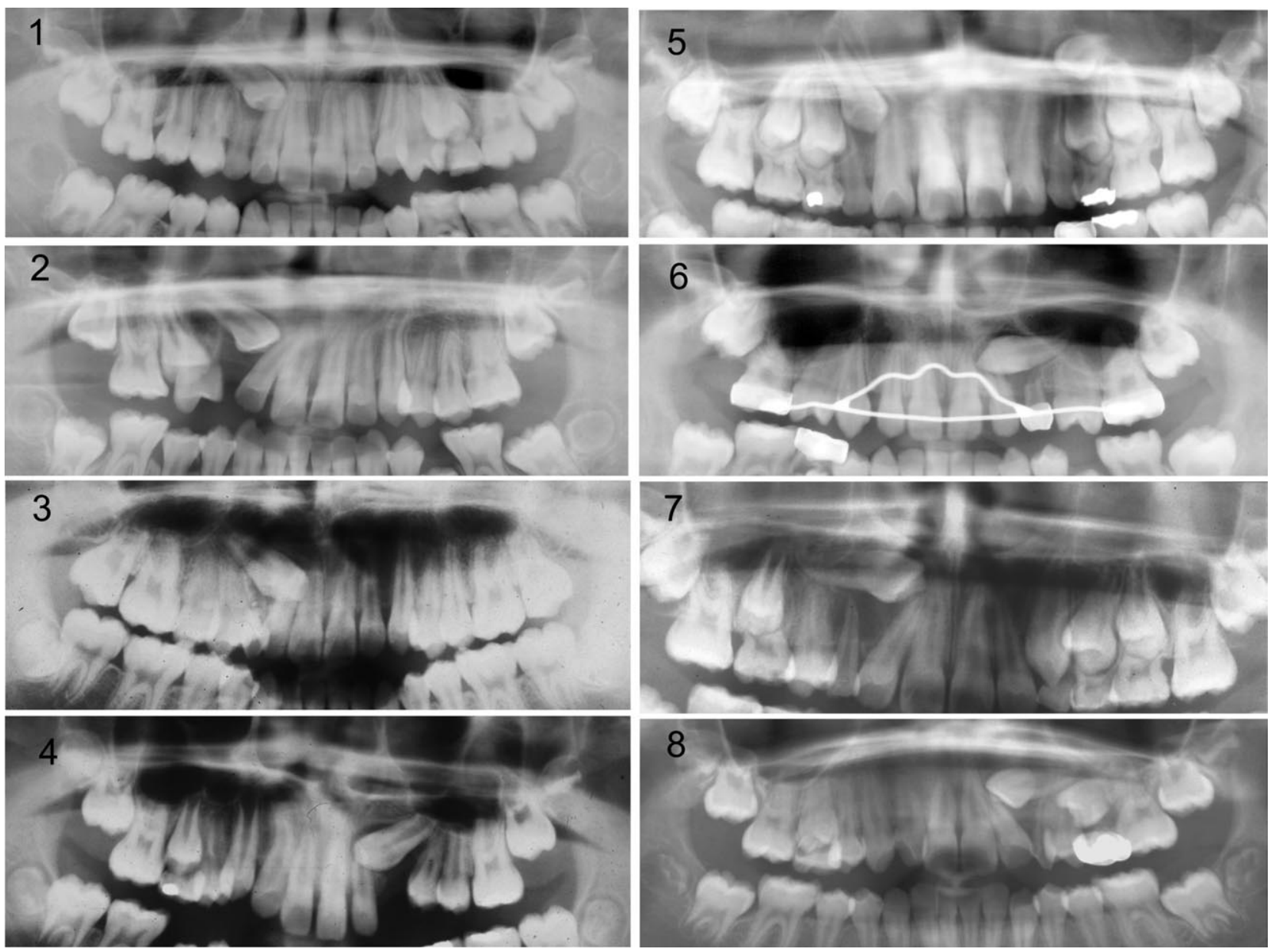

Fig. 2 The initial orthopantomograms in Cases 1 to 8

Arabic number corresponds to case number. Case 1, At 9-year-8-month-old; Case 2, At 12-year-2-month-old; Case 3, At 14-year-10-month-old; Case 4, At 11-year-9-month-old; Case 5, At 12-year-10-month-old; Case 6, At 13-year-2-month-old; Case 7, At 11-year-5-month-old; Case 8, At 11-year-0-month-old 

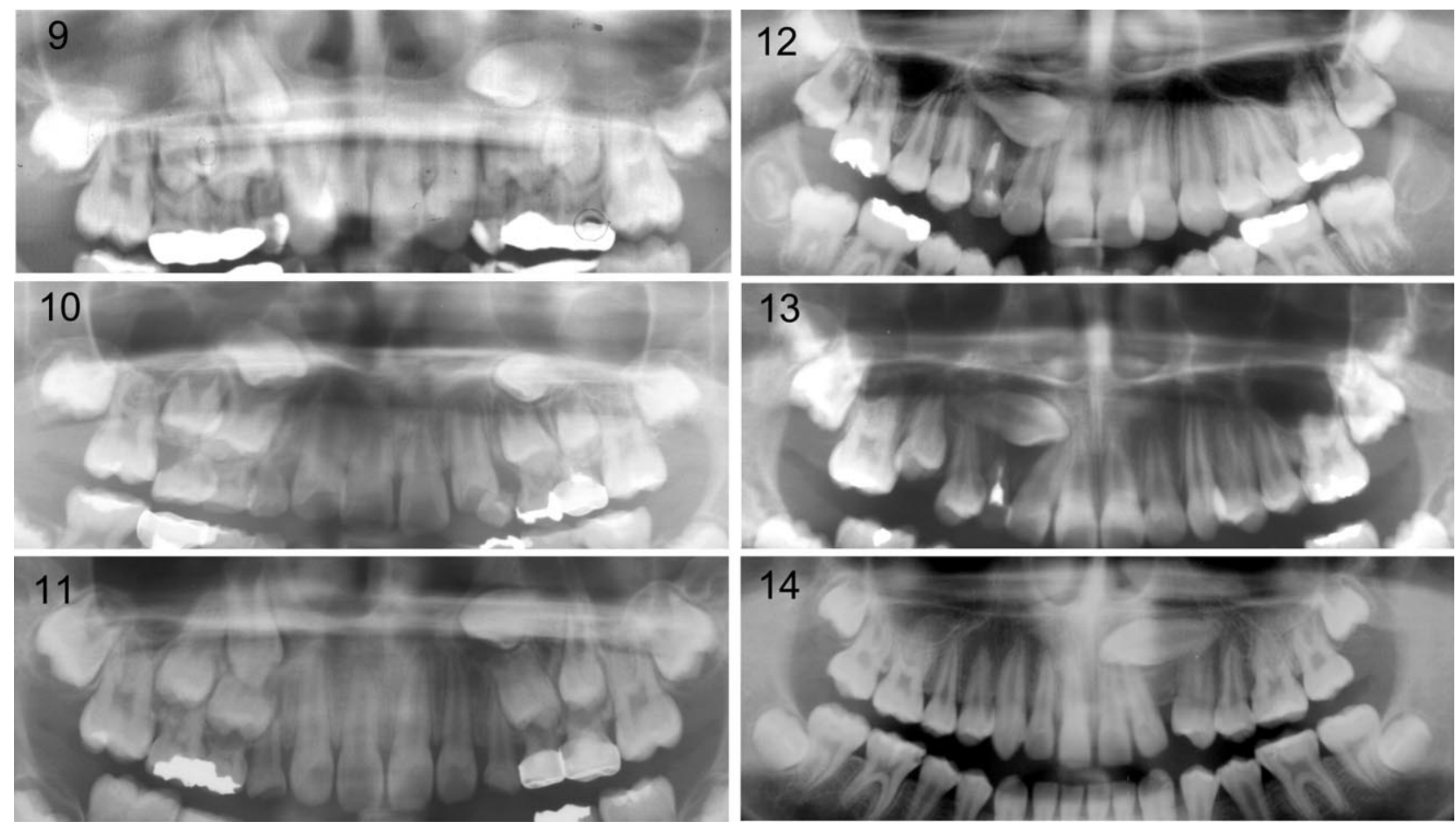

Fig. 3 The initial orthopantomograms in Cases 9 to 14

Arabic number corresponds to case number. Case 9, At 8-year-4-month-old; Case 10, At 8-year-6-month-old; Case 11, At 9-year-1-month-old; Case 12, At 11-year-0-month-old; Case 13, At 11-year-2-month-old; Case 14, At 12-year-7-month-old

Case No.

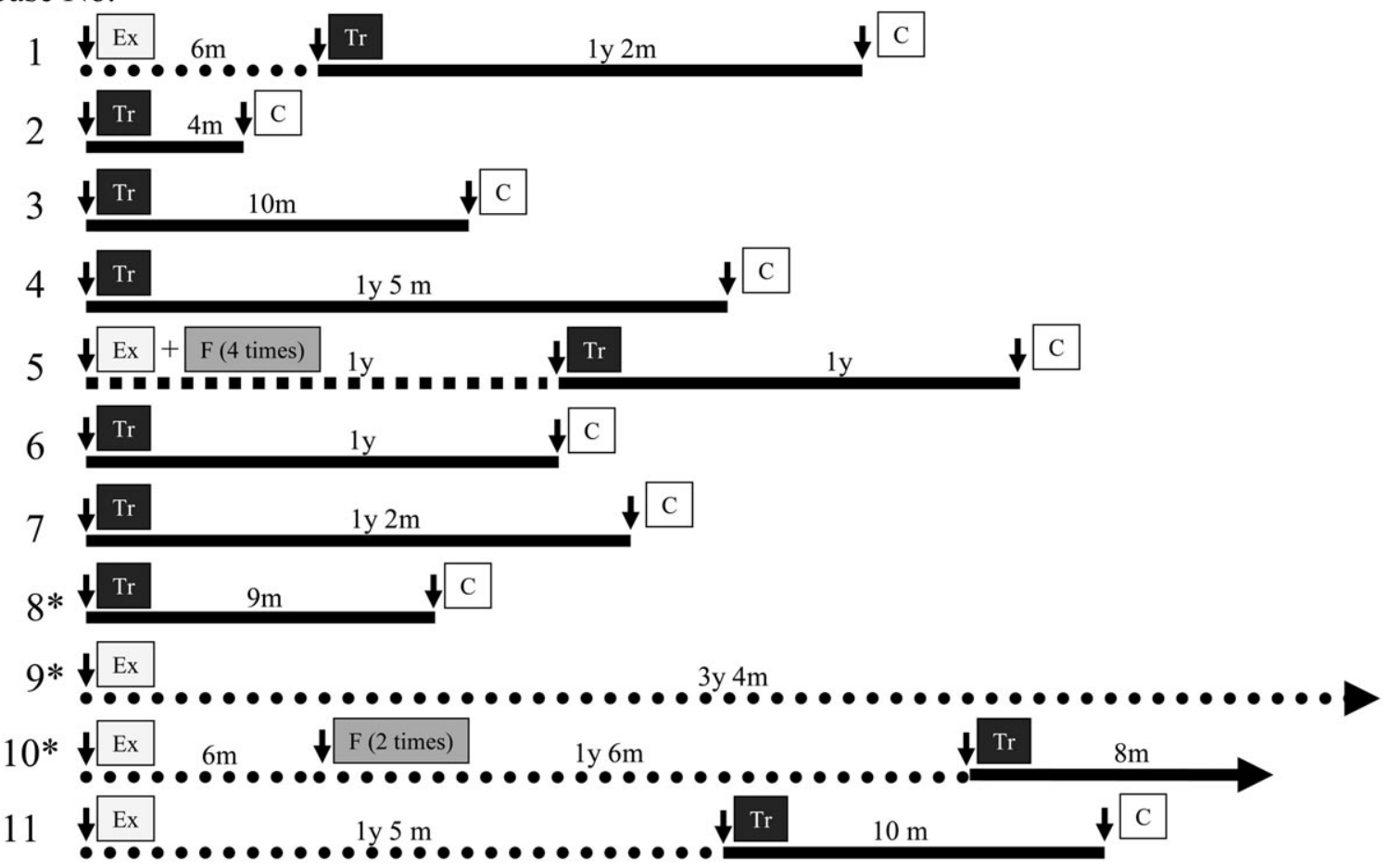

Fig. 4 Treatment sequence in each case except for three cases of removal

Ex, Extraction of the predecessor; F, Fenestration of the affected canine; Tr, Traction of the affected canine;

$\mathrm{C}$, Completion of alignment within the arch; *, Extraction of the first premolar 

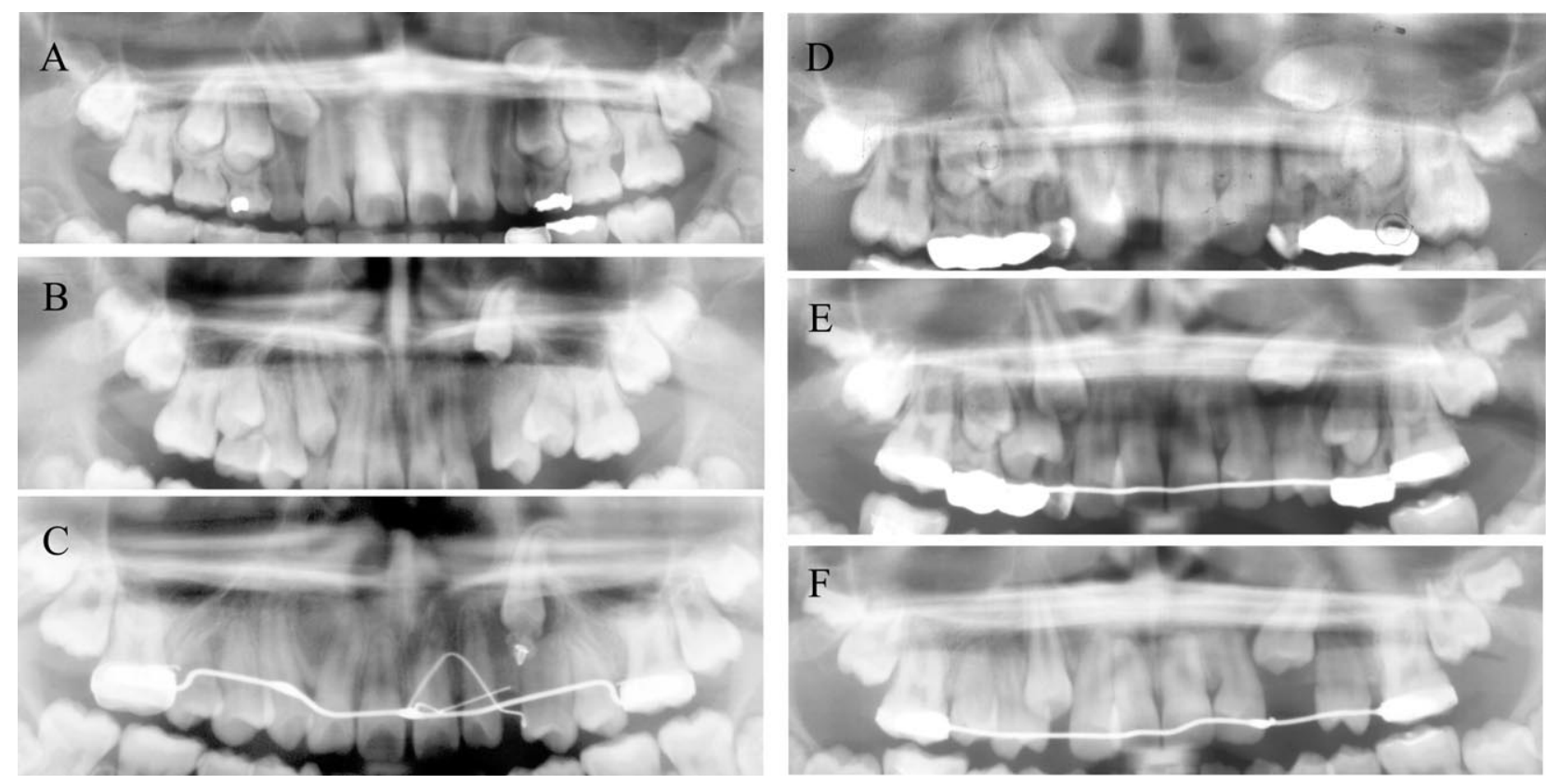

Fig. 5 Treatment course in Cases 5 (A-C) and 9 (D-F)

A, Extraction of the predecessor and the first fenestration on the start of treatment at the age of 12 years and 10 months in Case 5; B, 3 months later; C, 12 months later

D, Extraction of the predecessor on the start of treatment at the age of 8 years and 4 months in Case 9; E, Extraction of the left first premolar at 2 years and 2 months later; F, 3 years and 4 months after extraction of the predecessor

In Sector 1, on an orthopantomogram, the cusp tip of the affected canine was situated distally to the root of the lateral incisor. The affected canine in Sector 2 was overlapped on the distal half of the root of the lateral incisor and that in Sector 3 was on the mesial half of them. In the same way, Sectors 4 and 5 were classified by the position of the canine on the root of the central incisor. When the cusp tip was situated in Sectors 2 to 5 even without conspicuous mesial angulation, the canine could easily be diagnosed as anomalous.

From the ectopically erupting canines diagnosed by the above criteria, we selected as our subjects 14 severe cases in which mesial angulation exceeded 50 degrees (Table 1). Of these 14 cases, five were males and nine were females, and their ages at detection ranged from 8 years and 4 months to 14 years and 10 months. In Cases 9 and 10, although maxillary bilateral canines were affected, mesial inclination of only the left ones exceeded 50 degrees.

\section{Results}

The initial conditions of the ectopically erupting canines of our 14 cases are listed in Table 2, and the orthopantomograms taken before treatment in all cases are shown in Figs. 2 and 3. In Cases 1 to 11 except for Case 9, traction of the affected canine was needed for 4 to 17 months with or without extraction of the predecessor (Fig. 4). Fenestration was also performed twice or four times before traction in Cases 5 and 10. In Cases 8, 9 and 10, the maxillary left first premolar was extracted because of a space deficiency for the eruption of the affected canine. The ectopically erupting canines in Cases 12, 13 and 14 were removed since parental approval could not be obtained for the long-term traction required due to the severe position and angulation of canine tip and the uncertainty of the successful traction. The other reason to select the removal was that the impacted canine has the possibility to induce the root resorption of the adjacent incisors and that their parents offered orthodontic alignment after removal of the affected canines.

Of the present cases, there were common characteristics in the initial state of the ectopically erupting canines in four cases, Cases 5, 9, 10 and 11. Their mesial inclination ranged from nearly 80 to 90 degrees and the vertical lengths of their crown tip ranged between 30 and 37 millimeters, showing 

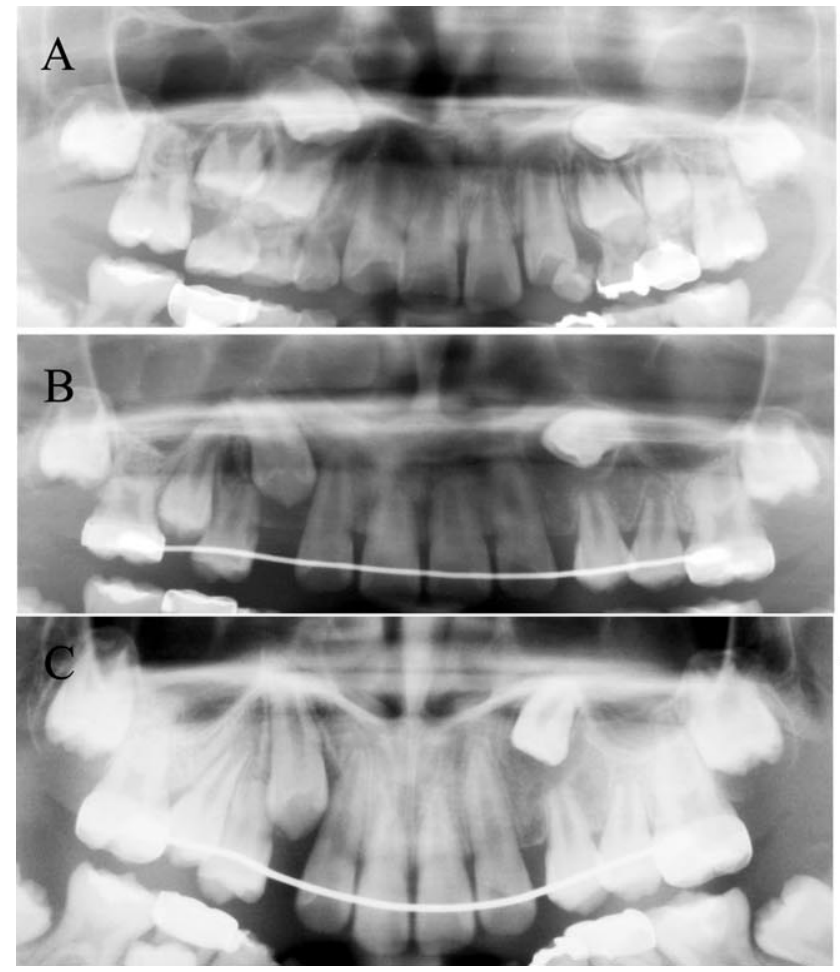

Sector 1 or 2 positioning (Table 2). They received no endodontic treatment for their predecessors, and their crown tips did not situate palatally.

In Case 5, the inclination and position of the left impacted canine was extremely improved 3 months after extraction of the predecessor and the first fenestration of the canine was performed (Fig. 5A, B). Although re-fenestration was then applied three times for 9 months, the canine hardly moved toward eruption (Fig. 5C). Traction of the affected canine was started and its alignment within the arch was completed after 1 year.

In Case 9, involving a patient who lived on a provincial island and could not make regular visits, we arranged for a private dentist on the island to extract the predecessor of the horizontally impacted left canine (Fig. 5D). Although the inclination of the canine was fairly improved 26 months after extraction (Fig. 5E), we offered again to extract the left first premolar because a space deficiency for the affected canine could be observed on the orthopantomogram sent by e-mail. The affected canine moved toward eruption gradually for 14 months (Fig. 5F) and the patient is now in the course of careful observation.

In Case 10, bilateral eruption disturbance of the

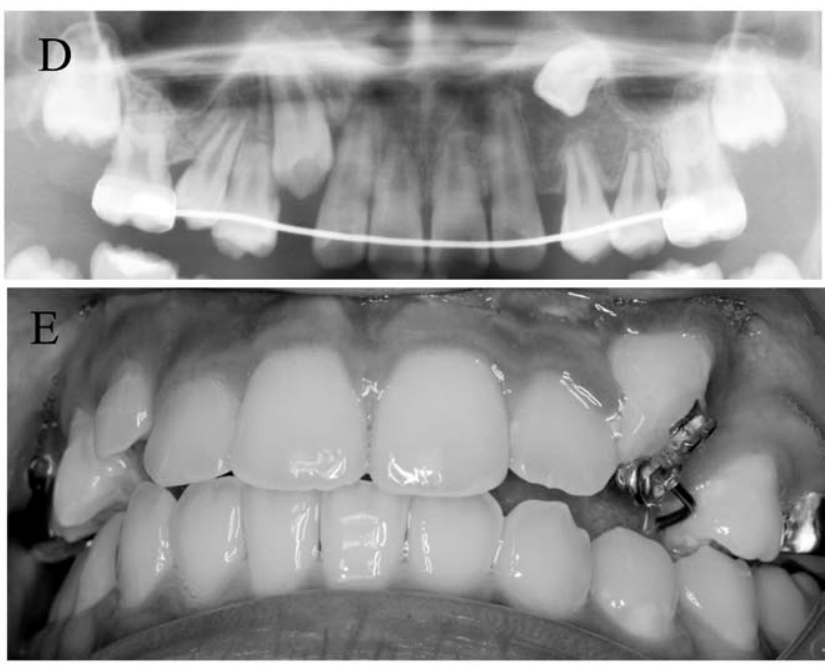

Fig. 6 Treatment course in Case 10

A, Extraction of the predecessor on the start of treatment at the age of 8 years and 6 months; B, The second fenestration at 12 months later; C, 3 months after the second fenestration; $\mathrm{D}$, Extraction of the left first premolar and the start of traction 6 months after the second fenestration; E, 8 months after the start of traction

maxillary canine was detected (Fig. 6A), showing inclinations of 90 degrees on the left side and 38 degrees on the right. Six months after the primary canines were extracted bilaterally, the first crown exposure of the left canine was performed. One year later (Fig. 6B), since the inclination and position of the affected canine showed no remarkable change, a second crown exposure was attempted for the left canine. The angulation of the canine became adequate 3 months after re-fenestration (Fig. 6C). Because the position of the canine did not show any change for the following 3 months (Fig. 6D) and a space deficiency for eruption was suspected, crown traction was started following the extraction of the left first premolar, and the canine has been now in the course of alignment within the arch (Fig. 6E). The right canine improved its initial situation and erupted spontaneously after extraction of the predecessor.

In Case 11, the axial angulation of the left canine was much improved 12 months after extraction of the predecessor (Fig. 7A, B). Five months after that, however, traction of the impacted canine was started since more improvement could not be expected based on the orthopantomogram (Fig. 7C). Traction and alignment of the canine was completed 10 months later (Fig. 7D, E). 

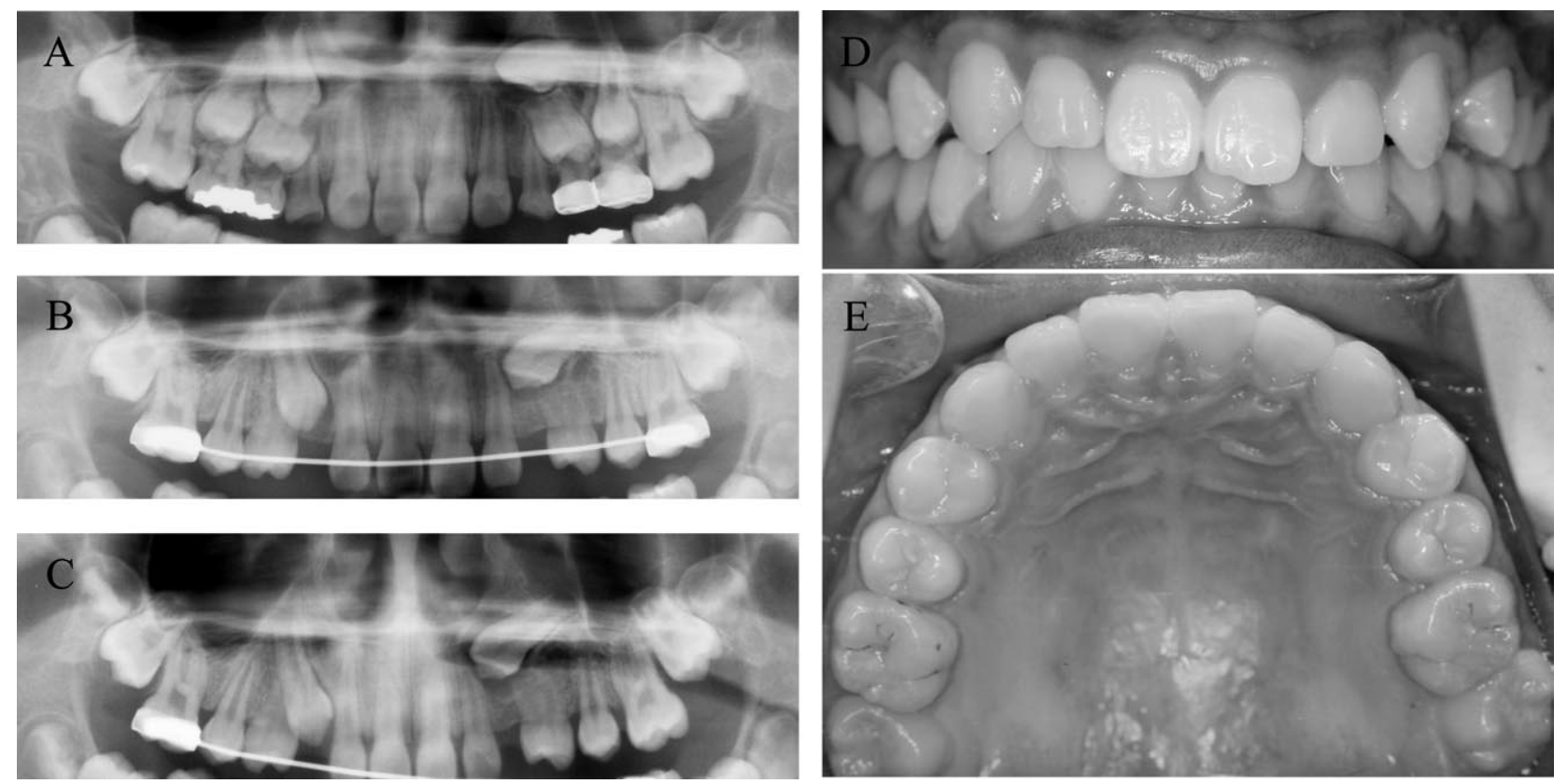

Fig. 7 Treatment course in Case 11

A, Extraction of the predecessor on the start of treatment at the age of 9 years and 1 month; B, 12 months later; C, The start of traction at 1 year and 5 months after extraction of the predecessor; D and E, 10 months after the start of traction

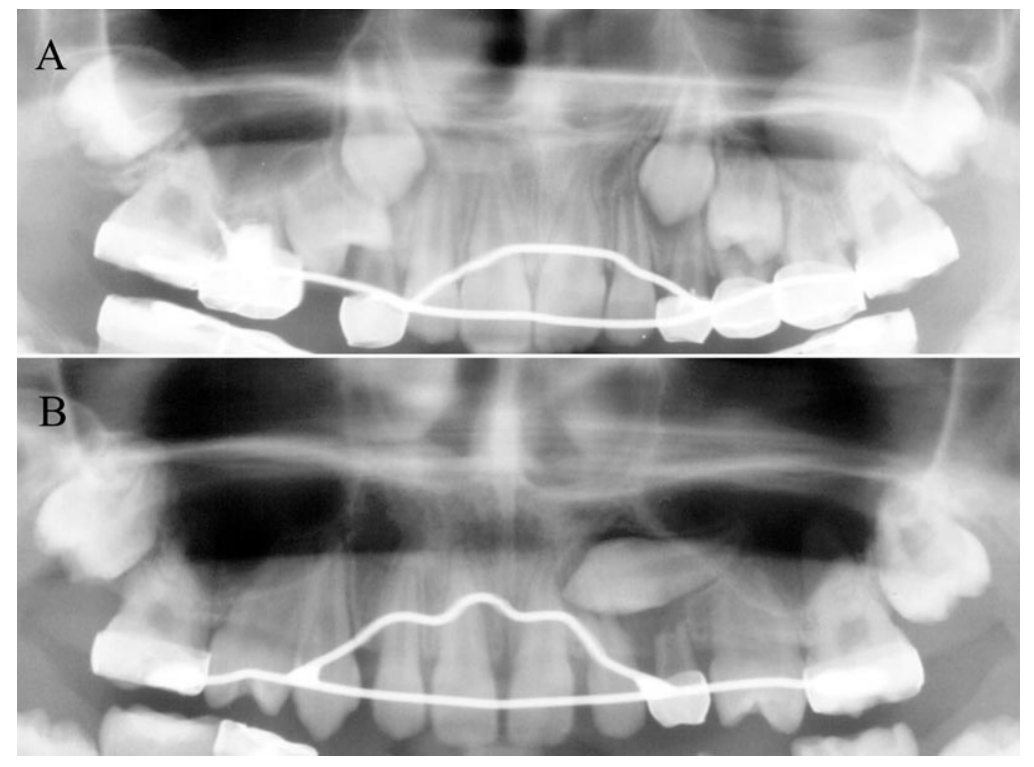

Fig. 8 Orthopantomograms in Case 6

A, At the age of 9 years and 1 month; B, At the age of 13 years and 2 months

\section{Discussion}

In the removal cases (Cases 12, 13 and 14), the crown top of the affected canines was located mesially beyond the midline of the lateral incisor root (Section 3, 4 and 5) and was situated in the palatal position, showing vertical lengths of 23 to 26 millimeters. On the other hand, the ectopically erupting canines of Cases 3, 4 and 6 were aligned without removal; they were located too far mesially 
(Sections 3 to 5) and palatally, similar to the removal cases, but their vertical lengths were 16, 19 and 20 millimeters, respectively, and shorter than those of the removal cases. This means that the vertical length to the occlusal line of the impacted canine influences the treatment complexity, as has been previously reported ${ }^{13,14,16)}$. Stewart et al. ${ }^{16)}$ elucidated that treatment of the palatally displaced canine required more time in cases with longer vertical lengths. In consideration of the above reports, we explained the surmised treatment course and duration for traction and alignment to the parents even in removal cases, including the possibility of unsuccessful traction, but could not attain parental consent. The parents selected orthodontic treatment after removal of the after canines.

Out of seven cases situated palatally, six had ever received endodontic treatment of their predecessors. In all removal cases, moreover, the affected canines were located palatally. In Japanese children, although the canine is palatally displaced less frequently than in Caucasians, the rate in palatally canines increases when the predecessor has a history of endodontic treatment ${ }^{15,17)}$. The present result indicates that it is important for us to monitor carefully the situation of the successors until their eruption when the primary canine is treated endodontically. In Case 6 (Fig. 8), eruption disturbance of the left canine was detected at the age of 13 years, but there was no abnormal sign of the canine on the orthopantomogram taken for confirmation of teeth development at the age of 9 years after the predecessor had been treated by pulpotomy. During the 4 years between X-ray examinations, eruption disturbance developed rapidly. This fact enforces us not to neglect monitoring the canines periodically in order to avoid unnecessary treatment of an ectopically erupting canine when the predecessor has already received endodontic treatment.

There were four similar ectopically erupting canines (Cases 5, 9, 10, 11), of which mesial inclination showed nearly 80 degrees or more and the vertical length reached over 30 millimeters with Sector 1 or 2 overlap. Since they received no endodontic treatment for their predecessors and relevant causes for them could not be detected, their severe mesial inclinations would be occurred by the developmental anomaly of tooth germ. The initial disruptive conditions of all four cases were improved after extraction of the predecessor and/or fenestration of the affected canine. For mild to moderate cases of ectopically erupting canine, it is well known that the first choice of treatment is extraction of the predecessor and that this preventive procedure can change the abnormal condition ${ }^{8-13)}$. The present study indicated that early extraction of the primary canine could also improve a severely ectopically erupting canine with excessive mesial inclination. When the affected canine improves and erupts downward, it can be easy to bond an attachment to the impacted tooth and make a successive traction. We recommend that traction should be postponed until a few months after extraction of the predecessor if the ectopically erupting canine is located far away from the occlusal line (over 30 millimeters) and its mesial inclination shows more than nearly 80 degrees; also that this treatment plan should be limited to cases in which the crown top belongs to Sector 1 and 2 .

\section{References}

1) Noda, T., Takagi, M., Hayashi-Sakai, S. and Taguchi, Y.: Eruption disturbances in Japanese children and adolescents. Ped Dent J 16: 50-56, 2006.

2) Dachi, S.F. and Howell, F.V.: A survey of 3,874 routine full-mouth radiographs: A study of impacted teeth. Oral Surg Oral Med Oral Pathol Oral Radiol Endod 14: 1165-1169, 1961.

3) Thilander, B. and Jakobsson, S.O.: Local factors in impaction of maxillary canines. Acta Odontol Scand 26: 145-168, 1968.

4) Grover, P. and Lorton, L.: The incidence of unerupted permanent teeth and related clinical cases. Oral Surg Oral Med Oral Pathol Oral Radiol Endod 59: 420425, 1985.

5) Sasakura, H., Yoshida, T., Murayama, S., Hanada, K. and Nakajima, T.: Root resorption of upper permanent incisor caused by impacted canine. Int $J$ Oral Maxillofac Surg 13: 299-306, 1984.

6) Ericson, S. and Kurol, J.: Incisor resorption caused by maxillary cuspids. A radiographic study. Angle Orthod 57: 332-346, 1987.

7) Kojima, R., Taguchi, Y., Kobayashi, H. and Noda, T.: External root resorption of the maxillary permanent incisors caused by ectopically erupting canines. $J$ Clin Ped Dent 26: 193-197, 2002.

8) Lappin, M.M.: Practical management of the impacted maxillary cuspid. Am J Orthod 37: 769-778, 1951.

9) Ericson, S. and Kurol, J.: Radiographic assessment of maxillary canine eruption in children with clinical signs of eruption disturbance. Europ J Orthod 8: 133-140, 1986.

10) Fernandez, E., Bravo, L.A. and Canteras, M.: Eruption of the permanent upper canine: A radiologic study. Am J Orthod Dentofac Orthop 113: 414-420, 1998.

11) Warford, J.H. Jr., Grandhi, R.K. and Tira, D.E.: 
Prediction of maxillary canine impaction using sectors and angular measurement. Am J Orthod Dentofac Orthop 124: 651-655, 2003.

12) Sambataro, S., Baccetti, T., Franchi, L. and Antonini, F.: Early predictive variables for upper canine impaction as derived from posteroanterior cephalograms. Angle Orthod 75: 28-34, 2005.

13) Taguchi, Y., Kobayashi, H. and Noda, T.: A diagnostic proposal to support early treatment of ectopically erupting maxillary canines. Ped Dent J 15: 52-57, 2005.

14) Kurol, J., Ericson, S. and Andreasen, J.O.: The impacted maxillary canine. In: Textbook and Color Atlas of Tooth Impaction. 1st ed. (Andreasen, J.O.,
Petersen, J.K. and Laskin, D.M. eds.) Munksgaard, Copenhagen, 1995, pp. 125-165.

15) Taguchi, Y., Kobayashi, H. and Noda, T.: The palatally displaced canine in Japanese children. Ped Dent J 10: 155-159, 2000.

16) Stewart, J.A., Heo, G., Glover, K.E., Williamson, P.C., Lam, E.W.N. and Major, P.W.: Factors that relate to treatment duration for patients with palatally impacted maxillary canines. Am J Orthod Dentofac Orthop 119: 216-225, 2001.

17) Taguchi, Y., Kobayashi, H. and Noda, T.: Eruption disturbances of maxillary permanent canines in Japanese children. Ped Dent J 11: 11-17, 2001. 